\title{
Phthalic Acid as a Reagent in Inorganic Qualitative Analysis of Metal Ions. Part I. A New System for Qualitative Analysis
}

\author{
PAAVOLUMME and JOUNI TUMMAVUORI
}

Department of Chemistry, University of Jyväskylä, Jyväskylä, Finland

\begin{abstract}
A new scheme for the qualitative chemical analysis of metal ions that is based on the use of phthalate ion as a precipitating reagent is outlined. Sulphide ion is not employed as a precipitating reagent. Evaporations of solutions are minimized and mineral acid and hy. drogen sulphide vapours in the laboratory atmosphere are avoided. The analysis scheme has worked well during twelve semesters (from June, 1968) when several hundreds of students have used it in our laboratory.
\end{abstract}

$\mathrm{T}$ he value of classical qualitative analysis in the teaching of chemistry has been discussed in, for example, the columns of the Swedish journal Svensk Kemisk Tidskrift in recent years. ${ }^{1}$ Opinions that stress the importance of the subject have been expressed but also derogatory ones. The fact remains that at least at present inorganic qualitative analysis offers the cheapest and most effective method for teaching and learning laboratory procedures and reactions of inorganic chemistry.

The greatest changes and improvements in qualitative analysis have resulted from the introduction of semimicro and micro methods and the replacement of precipitation with hydrogen sulphide by homogeneous precipitation with thioacetamide. ${ }^{3}$ A further step towards a more systematic analytical scheme was the introduction by West and Vick ${ }^{4}$ of precipitation with hydroxide and benzoate ions to replace precipitation with sulphide ions.

We have here in the Department of Chemistry at the University of Jyväskylä investigated this last-mentioned analytical scheme and its application as a method of instruction in inorganic qualitative analyses to freshmen and sophomore students and have come to the conclusion that phthalate ion (e.g., potassium biphthalate) is a better reagent than benzoate ion in combination with hydroxide ion as a precipitant. ${ }^{5-6}$ The alkaline earth metals calcium, magnesium, strontium, and barium are precipitated as their fluorides and certain divalent metal ions as their hydroxides with sodium hydroxide as in the scheme of West and Vick. ${ }^{4}$ In other respects the analytical scheme follows 
the classical scheme and the reactions of individual ions are the generally known customary ones. ${ }^{4,7}$

The analytical scheme that is briefly outlined below has been devised primarily for practical laboratory work and instruction and hence only the most essential aspects of the nature and reactions of the elements and their ions are presented ${ }^{5,6}$ The most noteworthy advantage of the presented analytical scheme in addition to its more systematic nature is the almost complete elimination of the evil-smelling, poisonous and corrosive hydrogen sulphide and the suppression of the evaporation of ammoniacal solutions and solutions containing mineral acids to a minimum. Also the costs of chemicals consumed are lower in the new scheme than in the earlier analytical schemes. The scheme does, however, require that the student exercises care in the handling of reagents and the adjustment of the $\mathrm{pH}$ values of the solutions.

\section{THE ANALYTICAL SCHEME}

The various ions that can be identified by following the analytical scheme and the reagents that divide them into groups are presented in Table 1 . The ions in parentheses are not included in the samples to be analysed in the early stages of instruction. The underlined ions are only rarely identified in the groups in question or they are transferred to the groups under exceptional conditions.

The sample of unknowns is examined by semimicro methods. Anions are analysed first. Preliminary tests that are extensively employed in many other analytical schemes have been omitted almost completely because the information they provide is of relatively minor significance from the point of view of systematic analysis. ${ }^{5,6}$

Table 1. The ions identified by the presented analytical scheme and their division into groups. ${ }^{5,6}$

\begin{tabular}{|c|c|c|}
\hline Group & Group reagent & Ions identified \\
\hline Anion group I & None & $\mathrm{NO}_{3}^{-}, \mathrm{HS}^{-}, \mathrm{S}^{2-}, \mathrm{HCO}_{3}^{-}, \mathrm{CO}_{3}{ }^{2-}$, \\
\hline Anion group II & None & $\mathrm{Cl}_{4}^{-}, \mathrm{Br}^{-}, \mathrm{I}^{-}, \mathrm{HSO}_{4}^{-} \mathrm{PO}_{4}^{-}, \mathrm{HPO}_{4}^{2-}$ \\
\hline $\begin{array}{l}\text { Cation group I } \\
\text { Cation group II }\end{array}$ & $\begin{array}{l}\mathrm{HCl} \\
\text { Potassium bi- } \\
\text { phthalate and }\end{array}$ & $\begin{array}{l}\mathrm{PO}_{4}{ }^{3-}, \mathrm{Ac}^{-}, \mathrm{AsO}_{2}{ }^{-}, \mathrm{AsO}_{4}{ }^{3-} \\
\mathrm{Ag}^{+}, \mathrm{Hg}_{2}^{2+}, \mathrm{Pb}^{2+} \\
\left(\mathrm{Sn}^{2+}\right),\left(\mathrm{Sn}^{4+}\right),\left(\mathrm{Sb}^{3+}\right), \\
\left(\mathrm{Bi}^{3+}\right), \mathrm{Fe}^{2+}, \mathrm{Fe}^{3+}, \mathrm{Al}^{3+},\left(\mathrm{Cr}^{3+}\right)\end{array}$ \\
\hline Cation group III & $\mathrm{NaF}$ & $\mathrm{Mg}^{2+}, \mathrm{Ca}^{2+},\left(\mathrm{Sr}^{2+}\right), \mathrm{Ba}^{2+}, \mathrm{Pb}^{2+}$ \\
\hline Cation group IV & $\mathrm{NaOH}$ & $\begin{array}{l}\mathrm{Mn}^{2+}, \mathrm{Hg}^{2+}, \mathrm{Cu}^{2+},\left(\mathrm{Co}^{2+}\right) \\
\left(\mathrm{Ni}^{2+}\right),\left(\mathrm{Cd}^{2+}\right)\end{array}$ \\
\hline Cation group $\mathrm{V}$ & $\mathrm{NH}_{4} \mathrm{OH}$ & $\mathrm{AsO}_{2}{ }^{-}, \mathrm{AsO}_{4}{ }^{3-}, \mathrm{Zn}^{2+},\left(\mathrm{Sn}^{2+}\right)$ \\
\hline Cation group VI & None & $\overline{\mathrm{Na}}^{+}, \mathrm{K}+\overline{\mathrm{NH}_{4}^{+}}$ \\
\hline
\end{tabular}


Identification of anions

Several systematic analytical schemes have been presented in the literature for the analysis of anions in groups, but they are mostly complicated and laborious. ${ }^{7}$ In the scheme presented here, the anions are not grouped on the basis of their analyticl properties but are mainly listed in the order in which they are effectively identified. This has been made possible by the relatively small numbers of anions that has been selected for identification by the scheme..$^{5,6}$

The anions of group I give gaseous products when they are treated with acid reagents and they are identified directly in the original sample in a simple gas detection unit. Also the presence of ammonium ion in the sample can be detected at this stage. Anions of group II are identified by means of the customary reactions in a solution of the sample from which heavy metals have been replaced by an alkali metal.?

\section{Identification of cations}

Investigation of the cations is begun directly on the original sample of unknowns if it is a solution or as a solution obtained by dissolving the sample in dilute mineral acid or base. If the sample contains a phase that dissolves with difficulty or if such a phase is formed when the sample is dissolved in dilute acid or base, it is separated from the other components of the sample, dissolved and examined separately.

Scheme 1. Precipitation and identification of group I cations.

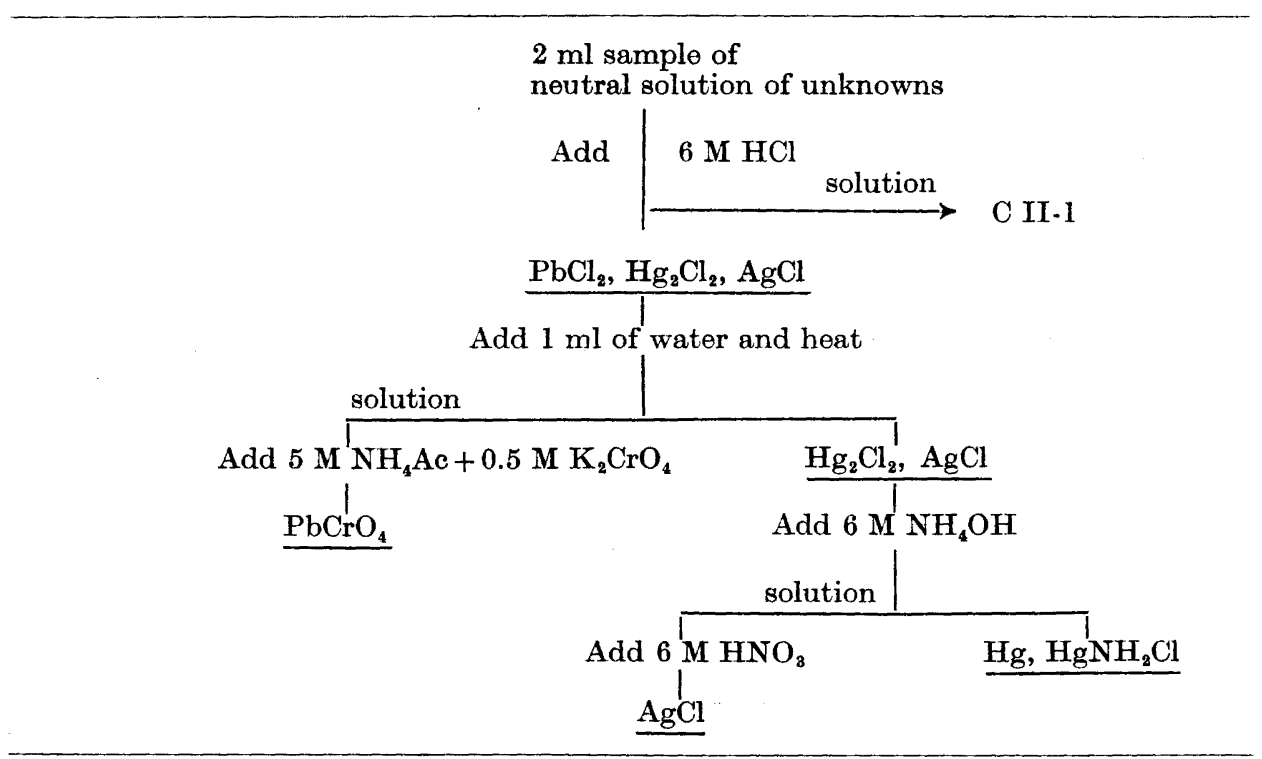

Customary tests are applied to identify the ions. ${ }^{4,7}$

Acta Chem. Scand. 27 (1973) No. 3 
Examination of cation group $I$. The tests are carried out on a practically neutral solution of the sample of unknowns. If the solution must be neutralized, this is done either with $6 \mathrm{M}$ nitric acid or with $6 \mathrm{M}$ sodium hydroxide.

The actual analysis is begun by taking a sample of the solution that is about $2 \mathrm{ml}$ in volume and adding $6 \mathrm{M}$ hydrochloric acid. If care is taken to avoid adding an excess of the reagent and the solution is cooled near $0^{\circ} \mathrm{C}$ before the precipitate is collected by filtration, the metals of the first group and lead are precipitated almost completely as chlorides. In the analytical schemes presented below, the precipitated compounds are underlined.

Examination of cation group II. Tests for the presence of cations of this group are done on the filtrate $(\mathrm{C} \mathrm{II}-1)$ collected after the cations of group I have been precipitated from the solution of the sample of unknowns which

Scheme 2. Precipitation and identification of group II cations.

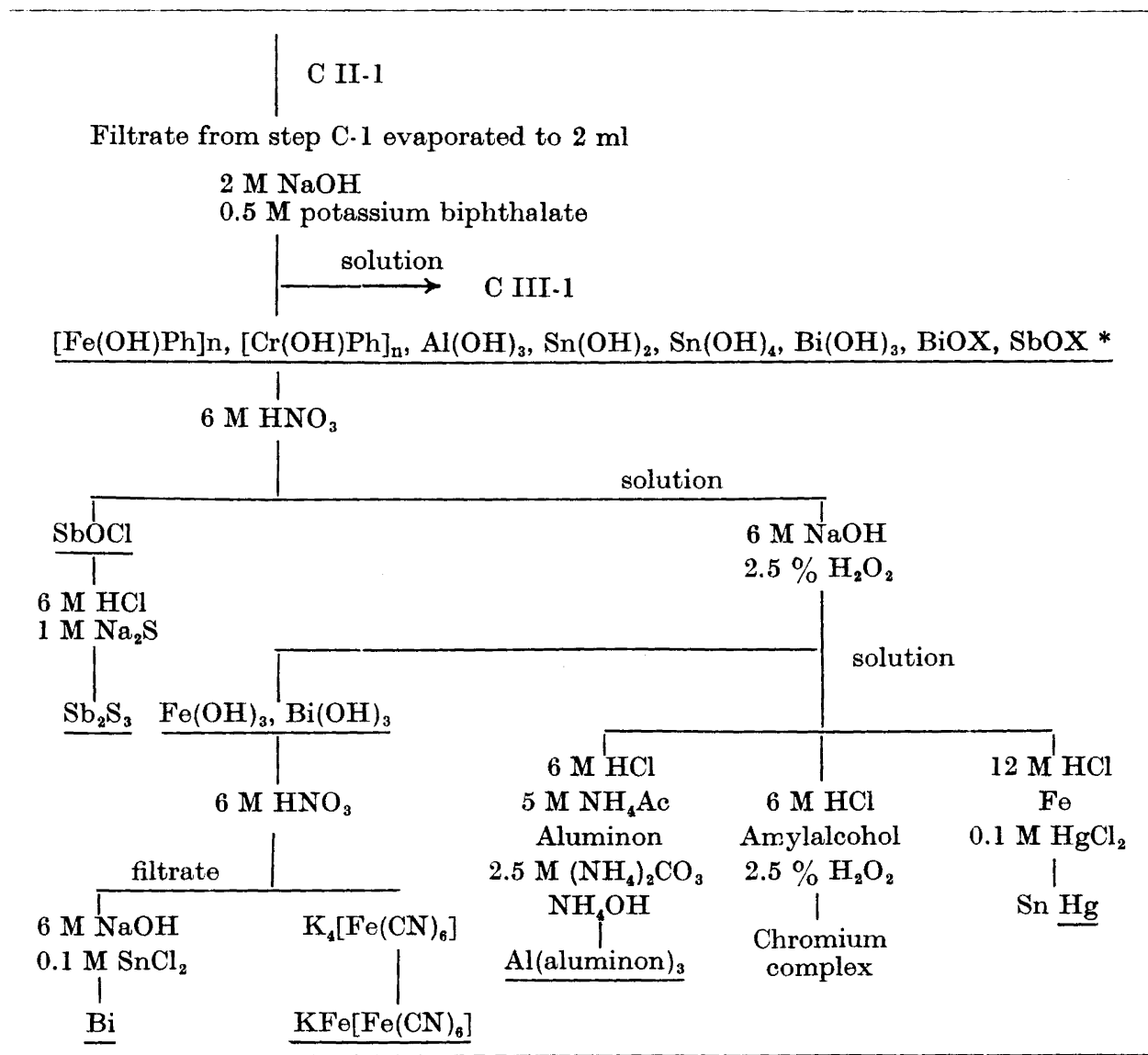

* Where $\mathrm{X}=\mathrm{Cl}^{-}, \mathrm{NO}_{3}^{-}$, or some other anion depending on the composition of the solution. The presented evaporations are the most probable ones.

The metals are identified by customary tests., ${ }^{4}, 7$ 
must be free from phosphate and borate ions. (If the sample solution contains phosphate or borate ions, these are removed with an ion exchange resin.) The $\mathrm{pH}$ of the filtrate is adjusted to 2 , several drops of $0.5 \mathrm{M}$ potassium biphthalate solution are added and the $\mathrm{pH}$ of the solution is adjusted to $4-5$ with sodium hydroxide solution. The solution is heated on a water bath for about $10 \mathrm{~min}$ during which the $\mathrm{pH}$ is checked to ensure that it remains between 4 and 5;

Scheme 3. Precipitation and identification of cations of group III.

\section{| C III-1}

Two millilitres of the filtrate collected in step C II-1

Saturated NaF solution

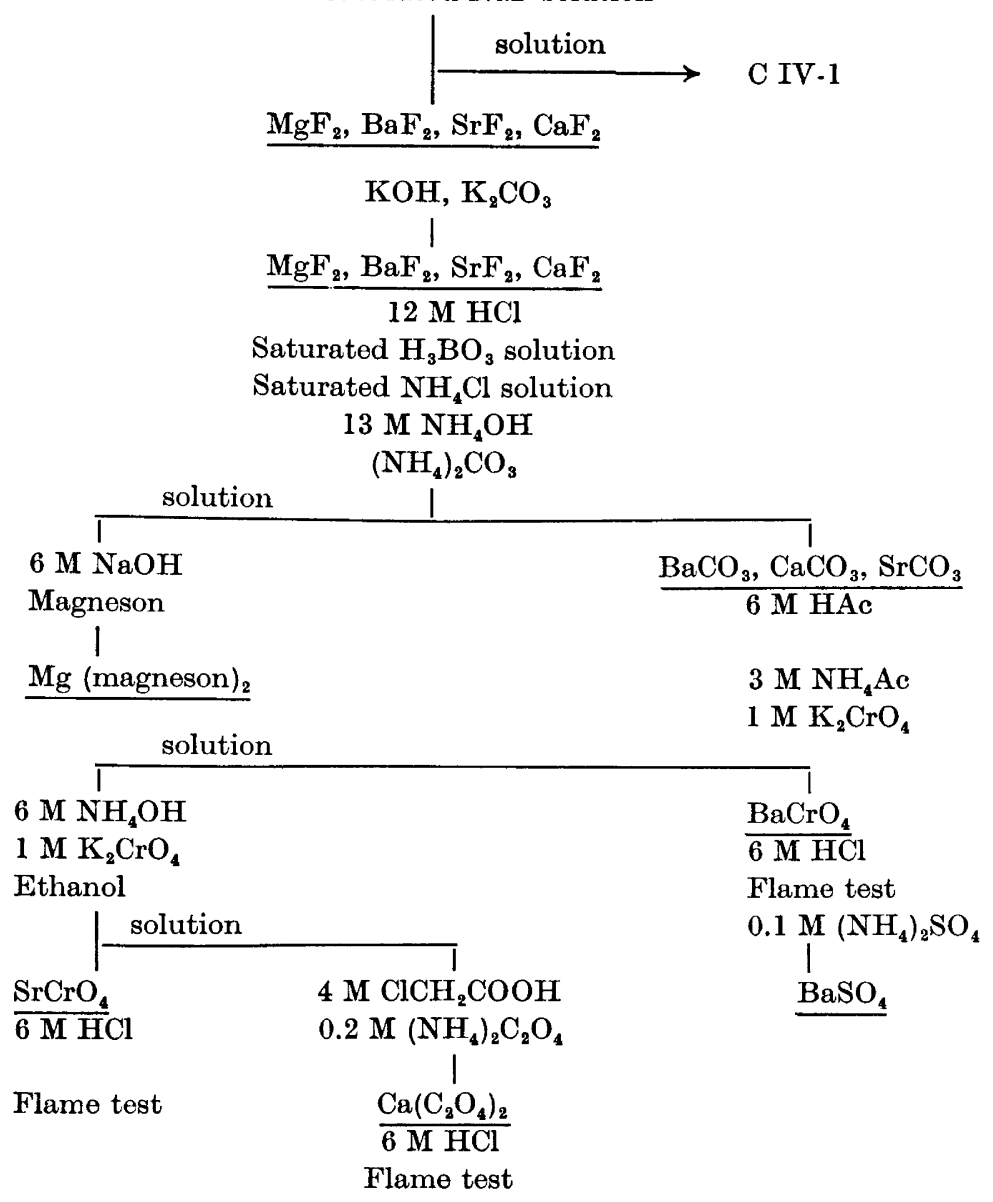

The group precipitate is examined further according to West and Vick ${ }^{4}$ and the metals are identified by means of customary reactions. ${ }^{4,9}$

Acta Chem. Scand. 27 (1973) No. 3 
any adjustments that are required are made with the precipitating reagents. It is essential that the solution is heated for $10 \mathrm{~min}$, because metals of other groups may otherwise coprecipitate, primarily as hydroxides. The solution and precipitate are cooled to room temperature and the precipitate is removed immediately by filtration. The cations precipitate as hydroxides, basic phthalates, and oxides of variable composition depending on the conditions. The composition of the group precipitate is discussed in part II. ${ }^{8}$

An excess of biphthalate must be avoided when this cation group is precipitated because some cations, particularly chromium, iron, and copper, readily form complex ions with phthalate ions and also because phthalic acid is sparingly soluble in water and may easily precipitate from acid solutions and thus interfere in later stages of the analysis.

Scheme 4. Precipitation and identification of cations of group IV.

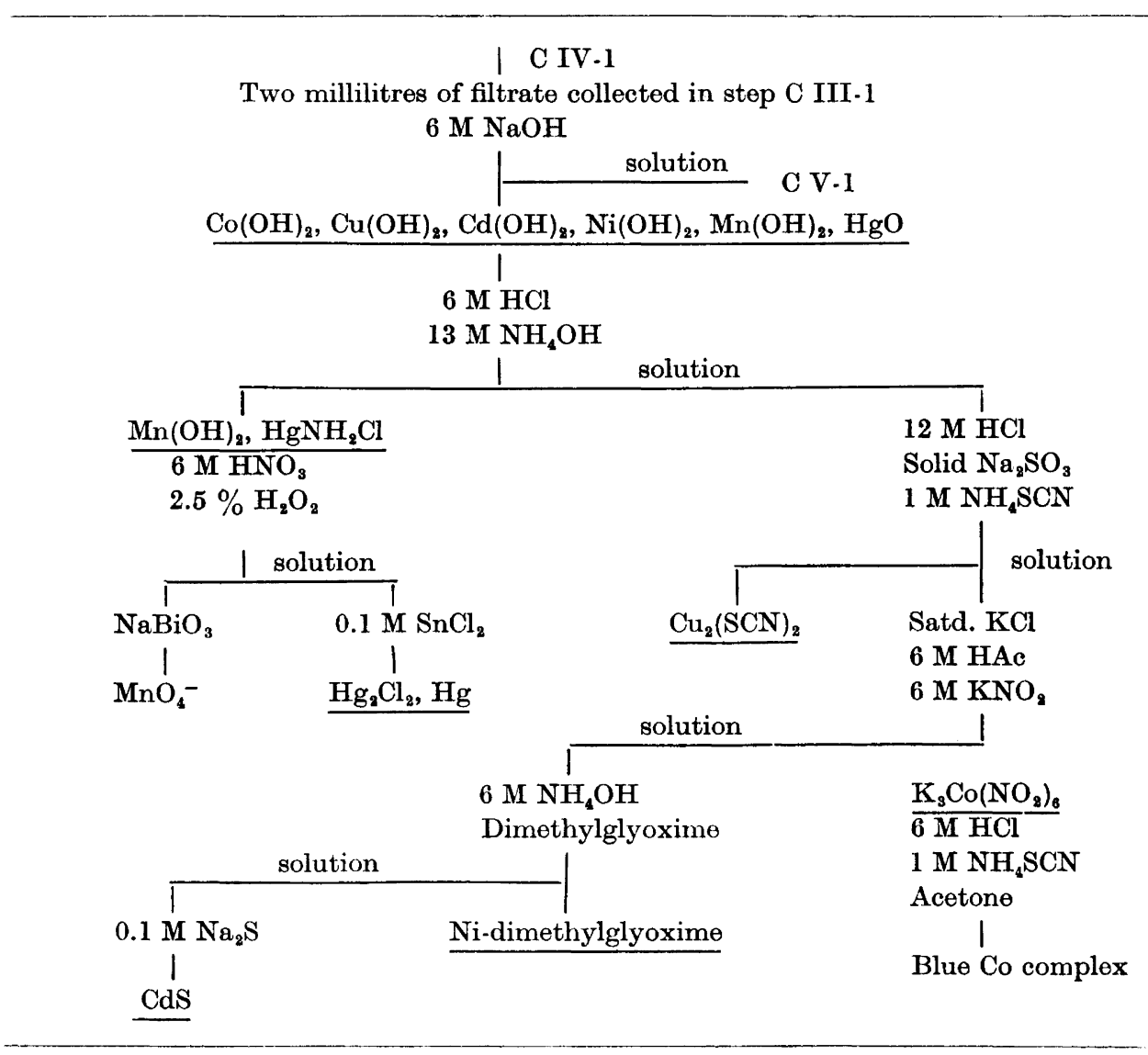

The metals are identified by customary tests.

Acta Chem. Scand. 27 (1973) No. 3 
Examination of cation group III. A saturated sodium fluoride solution is added to the filtrate collected after the precipitation of cations of group II and the solution is allowed to stand for at least 5 min with occasional stirring. The solution and precipitate are cooled near $0^{\circ} \mathrm{C}$ before the precipitate is collected by filtration.

Identification of group IV cations. The filtrate remaining after the cations of group III were precipitated is made clearly alkaline and the solution is evaporated until its volume is $2 \mathrm{ml}$, during which any ammonia present volatilizes. The cations of group IV precipitate mainly as hydroxides or oxides.

Examination of cation group $V$. The filtrate collected after precipitating group IV is evaporated to a volume of $2 \mathrm{ml}$ and acidified with hydrochloric acid. (Phthalic acid may precipitate at this stage, but is removed by filtration.) Ammonia is then added; in rare cases tin that has been transferred from cation group II may precipitate as stannous hydroxide. The solution is tested for the presence of arsenic and zinc., ${ }^{4}$ ?

Scheme 5. The examination of cation group V.

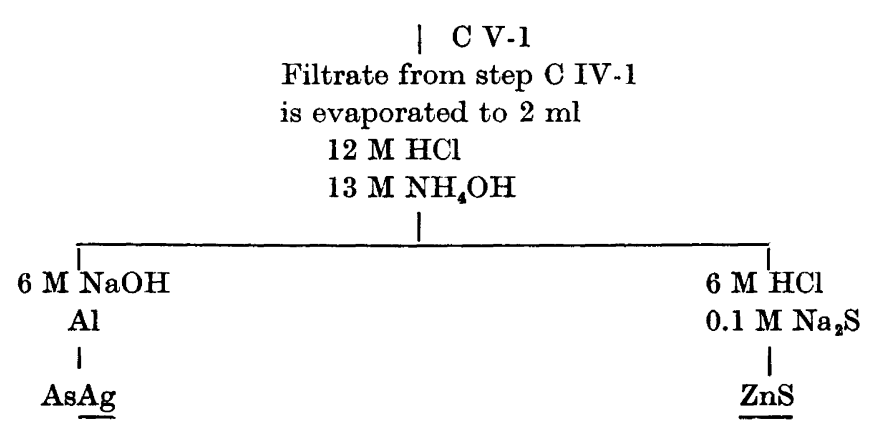

Examination of cation group VI. Tests for cations of this group are carried out on the original sample of unknowns in the order given in Scheme VI.

\section{SUMMARY}

The main advantages of the described analytical system involving the use of phthalate ion as a precipitating agent may be summarized as follows.

1. No difficulties are encountered in precipitating copper(II) and tin(II)ions as when benzoic acid is used as precipitating agent.4

2. Dibasic phthalic acid has a wider buffer range than monobasic benzoic acid and therefore the precipitation conditions are more easily controlled.

3. The formed heavy metal precipitates settle rapidly and are easily collected. In these respects the precipitates are at least as good as the precipitates obtained with benzoic acid. 
4. The formation of soluble phthalate or hydroxo complexes is avoided by immediate separation.

5. Phthalic acid is only about half as expensive as benzoic acid and ten times cheaper than thioacetamide.

Scheme 6. The examination of cation group VI.

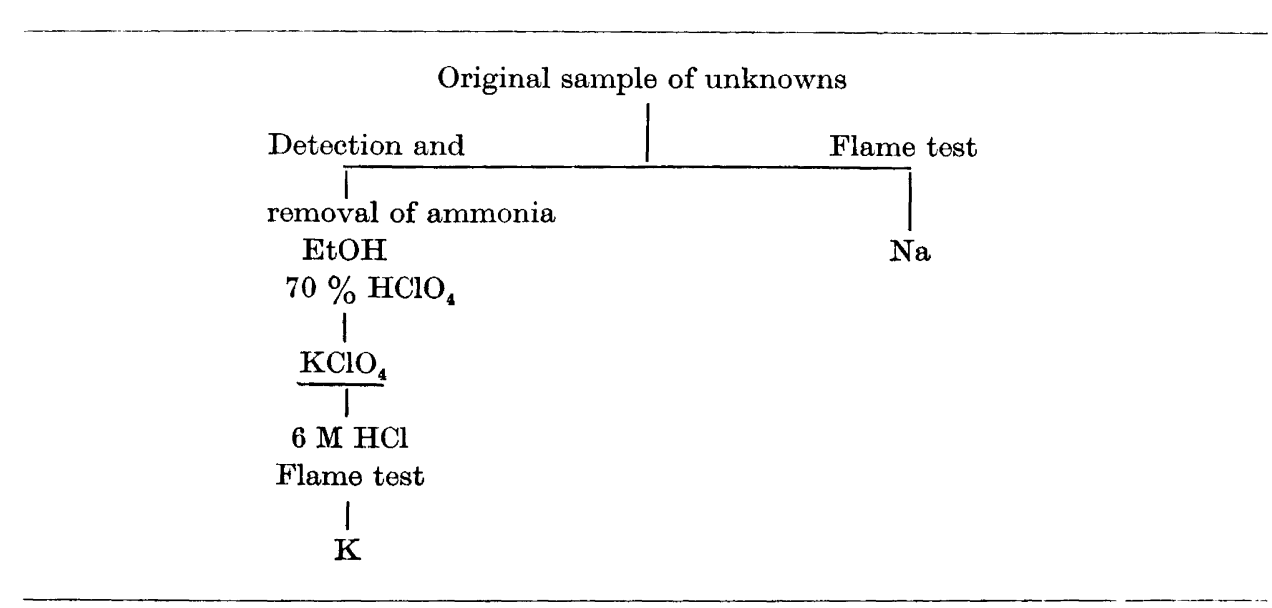

Acknowledgement. The authors are indebted to Mr. R. Korte, Ph.D. (h.c.) for the English translation of the manuscript.

\section{REFERENCES}

1. Mäcs, M. and Sundström, Y. Svensk Kem. Tidskr. 79 (1967) 192, and literature cited therein.

2. Stephen, W. I. Educ. Chem. 6 (1969) 221; Hovey, N. W. J. Chem. Educ. 40 (1963) 410.

3. Barber, H. H. and Grzeskowiak, E. Anal. Chem. 21 (1949) 192.

4. West, P. W. and Vick, M. M. Qualitative Analysis and Analytical Chemical Separations, 2nd Ed., MacMillan, New York 1959.

5. Lumme, P. O. and Tummavuori, J. Kemia II, Kvalitativinen analyysi approbaturarvosanaa varten, Jyväskylän yliopiston kemian laitos, Jyväskylä 1968. (In Finnish.)

6. Lumme, P. O. and Tummavuori, J. Kemia IV, Kvalitativinen analyysi approbatur- $j a$ cum laude-arvosanaa varten, Jyväskylän yliopiston kemian laitos, Jyväskylä 1968. (In Finnish.)

7. Treadwell, F. P. and Hall, W. T. Analytical Chemistry, Vol. I, Qualitative Analysis, 9th Ed., Wiley, New York 1963.

8. Lumme, P. and Tummavuori, J. Acta Chem. Scand. To be published.

Received September 1, 1972. 